\title{
Intranasal Administration of Conditioned Medium from Cultured Mesenchymal Stem Cells Improves Cognitive Impairment in Olfactory Bulbectomized Mice
}

\section{Kazuhiro Kojima1, Ichiro Kawahata1, Hisanao Izumi1, Sei-ichi Yoshihara², Katsuyuki Oki², Kohji Fukunaga ${ }^{*}$}

${ }^{1}$ Department of Pharmacology, Graduate School of Pharmaceutical Sciences, Tohoku University, Sendai, Japan

${ }^{2}$ BioMimetics Sympathies Inc., Tokyo, Japan

Email: *kfukunaga@tohoku.ac.jp

How to cite this paper: Kojima, K., Kawahata, I., Izumi, H., Yoshihara, S., Oki, K. and Fukunaga, K. (2020) Intranasal Administration of Conditioned Medium from Cultured Mesenchymal Stem Cells Improves Cognitive Impairment in Olfactory Bulbectomized Mice. Advances in Alzheimer's Disease, 9, 47-56.

https://doi.org/10.4236/aad.2020.93004

Received: August 1, 2020

Accepted: September 4, 2020

Published: September 7, 2020

Copyright $\odot 2020$ by author(s) and Scientific Research Publishing Inc. This work is licensed under the Creative Commons Attribution International License (CC BY 4.0).

http://creativecommons.org/licenses/by/4.0/

\begin{abstract}
Alzheimer's disease $(\mathrm{AD})$ is the common cause of dementia which shows the neuro-pathologies like an accumulation of amyloid- $\beta(\mathrm{A} \beta)$ and degeneration of cholinergic neuron. Olfactory bulbectomized (OBX) mice show some of $\mathrm{AD}$ features, so they have been used to research as AD model. Mesenchymal stem cells (MSCs) can differentiate into many kinds of cells, including neuronal cells. In this study, we intranasally administrated the conditioned medium derived from cultured umbilical cord (UC) MSCs. The intranasal administration of the MSCs medium restored the cognitive impairment observed in OBX mice. In addition, the decreased number of choline acetyltransferase-positive cells in the medial septum was restored by the conditioned medium administration. In conclusion, MSCs-derived conditioned medium may have protective effects of cholinergic neurons in the medial septum, thereby rescuing the cognitive impairment of OBX.
\end{abstract}

\section{Keywords}

Alzheimer's Disease, Cholinergic Neuron, Olfactory Bulbectomy, Mesenchymal Stem Cells (MSCs), MSCs-Derived Conditioned Medium

\section{Introduction}

Alzheimer's disease (AD) is a common disorder associated with cognitive impairment. $\mathrm{AD}$ is characterized by amyloid- $\beta(\mathrm{A} \beta)$ plaque and intracellular neurofibrillary tangles (NFTs) [1]. Donepezil, rivastigmine and galantamine, the ace- 
tylcholine esterase (AChE) inhibitors, and memantine, an N-methyl-D-aspartate (NMDA) receptor antagonist, are currently prescribed for AD therapy. However, those medicines can only prevent the progression of AD's symptoms and not be able to cure them fundamentally. Recently, $\beta$-secretase inhibitor and anti-A $\beta$ antibody are received attention for new therapeutic agents, but these compounds have not succeeded in recovering AD symptoms yet [2] [3] [4] [5] [6].

Olfactory bulbectomized (OBX) mice are a useful model of $\mathrm{AD}$ because they represent the pathological characteristics observed in $\mathrm{AD}$ such as $\mathrm{A} \beta$ accumulation, cognitive impairment and depression. For example, OBX mice showed a loss of memory deficits mediated by cholinergic neuronal dysfunction [7]. Also, the $\mathrm{A} \beta$ level in neocortex and hippocampus was increased by bulbectomy [8]. We previously demonstrated that donepezil rescues the medial septum cholinergic neurons via the activation of nicotinic acetylcholine receptors in OBX mice [9]. We further showed that ST101 treatment improved memory impairment associated with the increased phosphorylation of $\mathrm{Ca}^{2+} /$ calmodulin-dependent protein kinase II (CaMKII) and protein kinase C (PKC) in the hippocampus via activation of T-type voltage-gated calcium channel [10] [11].

Mesenchymal stem cells (MSCs), which reside in bone marrow, adipose tissue and umbilical cord, etc. can differentiate many kinds of mesenchymal tissues, including bone, muscle, and stroma [12]. In addition, MSCs can mature into neuronal cells [13]. Some recent studies show that MSCs have protective effects on Alzheimer's disease [14] [15]. We here found that the administration of conditioned medium derived from UC MSCs had a protective therapeutic effect in OBX mice. In addition, we provide the evidence that the conditioned medium of UC MSCs affects on survival of medial septum cholinergic neurons.

\section{Materials and Methods}

\subsection{Animals and Operation of Olfactory Bulbectomy}

Eight-week-old male ddY mice were purchased from CLEA Japan, Inc. (Tokyo, Japan). The average weight of the mice was $38 \mathrm{~g}$. Animals were bred under conditions of $23^{\circ} \mathrm{C} \pm 2^{\circ} \mathrm{C}$, humidity $55 \% \pm 5 \%$, light and dark cycle (light from 9 am to $9 \mathrm{pm}$ ), and unlimited access to food and water. All experimental procedures conformed to "Regulations for Animal Experiments and Related Activities at Tohoku University" and were reviewed by the Institutional Laboratory Animal Care and Use Committee of Tohoku University. After habituation for 1 week, OBX mice were prepared as described previously [16]. In brief, mice were anesthetized and their head immobilized by a stereotaxic apparatus (David Kopf Instruments, Tujunga, CA, USA). A small burr hole was drilled on both sides of the olfactory bulbs, which were then removed using a suction pump. Holes were filled with hemostatic sponges to prevent hemorrhagia.

\subsection{UC MSC Conditioned Medium Preparation}

Human UC tissues were collected from full-term pregnant women who provided 
informed consent at Narita Ladies' Clinic (Saitama, Japan). The sampling collection has been approved by the Human Ethics Committee in Narita Ladies' clinic as well as BioMimetics Sympathies Inc., and the UC tissues are not be collected without patient consent. UC-MSCs were isolated from the sample, and stromal vascular fraction were passaged with sf-DOT (BioMimetics Sympathies, Inc., Tokyo, Japan), a serum-free culture medium, at $37^{\circ} \mathrm{C}$ in an atmosphere containing $5 \% \mathrm{CO}_{2}$. About $1.2 \times 10^{6} \mathrm{UC}$-MSCs of passage 5 were seeded in each T175 CellBIND culture flask containing $30 \mathrm{ml}$ of sf-DOT medium. After 5 days of incubation, resulting MSC-CM was collected, centrifuged at $400 \mathrm{~g}$ for $5 \mathrm{~min}$ to remove the cell debris, filtered through $0.22-\mu \mathrm{m}$ filter, and then concentrated (10 times) by ultrafiltration using centrifugal filtering units with a cut-off value of 3 $\mathrm{kDa}$ (Amicon Ultra-15; Millipore, MA), according to the manufacturer's instructions. The concentrated UC MSC-CM was aliquoted and stored at $-20^{\circ} \mathrm{C}$ until use.

\subsection{Intranasal Administration of Medium and Conditioned Medium for OBX Mice}

We conducted the following experiments as shown in Figure 1. During 14 days from OBX operation, nasal administration of the control medium or the conditioned medium was performed 5 times. After the treatment, we conducted behavior tests and immunohistochemical analysis. Intranasal administration was conducted for OBX mice in 2nd, 4th, 7th, 10th and 12th day after the operation (Control medium: $20 \mu \mathrm{L}$; Conditioned Medium: 10 or $20 \mu \mathrm{L}$ each day).

\subsection{Behavioral Tests}

Three behavioral tests were conducted 14 days later from OBX operation.

\subsection{Y-Maze Task}

A Y-maze task that can measure spatial memory was conducted as previously described [16]. A mouse was put on the end of the arm and allowed to move freely

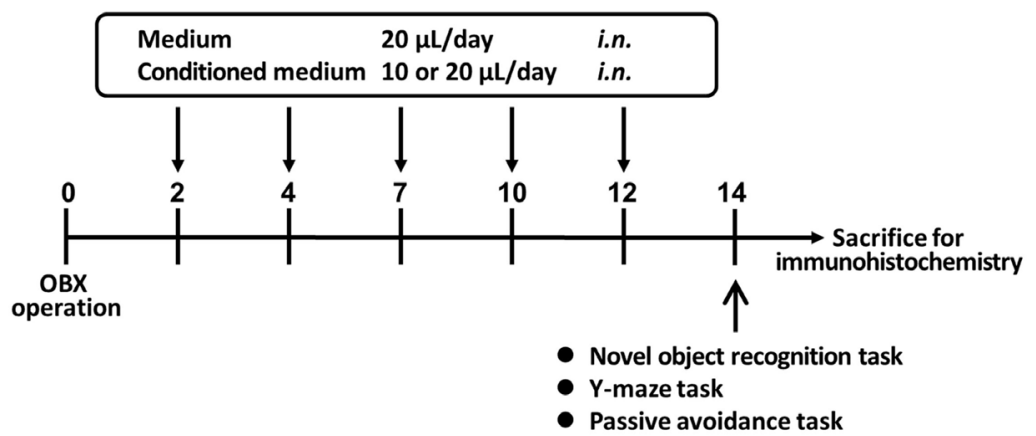

Figure 1. Protocol of the treatment of conditioned medium for olfactory bulbectomized (OBX) mice. OBX mice were treated with the conditioned medium at 2, 4, 7, 10, and 12 days after bulbectomy. Two weeks later, novel object recognition task, Y-maze task, and passive avoidance task were conducted. The brain sections of the OBX mice were immunostained after finishing the behavior tests. 
for 8 minutes. Alternation behavior was defined as entries into all three arms on consecutive choices. Percentage of alternation was calculated as (alternation)/(total arm entries -2$) \times 100$.

\subsection{Novel Object Recognition Task}

Novel object recognition task is based on the characteristics that mice prefer novel objects to familiar ones. In the trial session, two similar objects were placed on the mouse cage symmetrically, and then the mouse was put on the cage for 10 minutes. 24 hours later, one of the objects was replaced with a novel one and let the mice explore in the cage for 5 minutes (called "test session"). A discrimination index was evaluated by comparing the difference between exploratory contacts of novel or familiar objects and the total number of contacts, adjusting for differences in total exploration contacts.

\subsection{Step-Through Passive Avoidance Task}

Passive avoidance task was conducted as previously described [16]. The apparatus consisted of light and dark compartments with stainless steel rods connected with an electronic stimulator (Muromachi Kikai, Tokyo, Japan). After putting a mouse on the light compartment, When the mouse entered the dark compartment, it received an electric shock ( $0.3 \mathrm{~mA}$ for $2 \mathrm{~s}$ ) from the grid floor and was removed from the apparatus $30 \mathrm{~s}$ later on training trials (fear acquisition). 24 hours after this fear acquisition session, mice were placed in the light compartment and step-through latency was recorded over a period of $300 \mathrm{~s}$, an indicator of retention level (test session).

\subsection{Immunocytochemistry}

Mice were perfused with ice-cold phosphate-buffered saline (PBS, pH 7.4) and then with $4 \%$ paraformaldehyde. After removal and postfixation of the brain, tissue was sliced into $50 \mu \mathrm{m}$-thick coronal sections using a vibratome (Dosaka EM, Kyoto, Japan). TSA immunohistochemistry was performed using TSA Fluorescein System kit (PerkinElmer, MA, USA). The sections were incubated with $0.3 \% \mathrm{H} 2 \mathrm{O} 2$ in $\mathrm{PBS}$ for 30 minutes to inactivate endogenous peroxidase. After blocking with TSA buffer (containing $5 \mathrm{~mL} 2 \mathrm{M}$ Tris- $\mathrm{HCl}, 0.88 \mathrm{~g} \mathrm{NaCl}$ and $0.5 \mathrm{~g}$ blocking reagent in the kit per $100 \mathrm{~mL}$ ), mouse anti-ChAT (1:500 in TSA buffer, Millipore) diluted in blocking solution was added and incubated in $4^{\circ} \mathrm{C}$ for overnight. Washing with PBS several times, biotinylated anti-mouse antibody (1:500 in TSA buffer) was reacted for 2 hours at $4^{\circ} \mathrm{C}$. Then, streptavidin-HRP (1:500 in TSA buffer) was added and incubated for 2 hours at $4^{\circ} \mathrm{C}$ after PBS washing. Finally, the sections were incubated with the fluorescein tyramide reagent (1:100 diluent) for $10 \mathrm{~min}$ in room temperature in the dark and enclosed by MAS coated microscope slide immersed in VECTASHIELD ${ }^{\circledR}$ Antifade Mounting Media (Vector Laboratories, CA, United States). Images were acquired by confocal laser scanning microscope (TCS SP8, Leica Microsystems, Wetzlar, Germany). 


\subsection{Statistical Analysis}

All data were presented as means \pm standard error of the mean (S.E.M). Statistical significance was tested by one-way analysis of variance (ANOVA) followed by Tukey's post hoc test. Pairs of means were compared by Student's $t$-test. All the statistical analyses were performed using GraphPad Prism 8 (GraphPad Software, CA, USA). Differences with $p<0.05$ were considered statistically significant.

\section{Results}

\subsection{Intranasal Administration of Conditioned Medium Improves the Memory Deficit Seen in OBX Mice}

First, we investigated whether conditioned medium can recovery impaired memory of OBX mice by three behavior tests. In Y-maze task, OBX mice showed a decrease of alternation compared with sham-operated mice $(53.12 \% \pm 2.89 \%, p$ $<0.01$ vs. sham; Figure $2(\mathrm{~b})$ ). Intranasal administration of conditioned medium $(20 \mu \mathrm{L})$ restored memory loss without alteration of total arm entries $(71.19 \% \pm$ $3.11 \%, p<0.05$ vs. OBX; Figure 2(a) and Figure 2(b)). The discrimination index was measured by a novel object recognition task. In the trial session, there are no differences in the discrimination index in all groups (Figure $2(\mathrm{c})$ ). In the test session, OBX mice could not discriminate a novel object from familiar one $(48.96 \% \pm 1.87 \%, p=0.44$ vs. familiar; Figure $2(\mathrm{~d}))$. On the other hand, the administration of conditioned medium restored memory deficit observed in OBX mice $(59.65 \% \pm 2.15 \%, p<0.001$ vs. familiar; Figure $2(\mathrm{~d}))$. In the fear acquisition session of passive avoidance task, mice in all groups entered the dark box immediately (Figure 2(e)). In the test session, latency time of OBX mice was significantly shorter than that of sham-operated mice (16.95 \pm 4.75 sec, $p<0.0001$ vs. sham; Figure 2(f)) and the memory impairment was recovered by conditioned medium treatment $(228.12 \pm 50.99 \mathrm{sec}, p<0.0001$ vs. OBX; Figure 2(f)).

\subsection{The Administration of Conditioned Medium Restores Decreased ChAT-Positive Cells in the Medial Septum}

After examining the behavioral test, we conducted immunostaining of medial septum to analyze the therapeutic effect of conditioned medium on the gene expression of acetyltransferase (ChAT) in OBX mice (Figure 3(a)). Consistent with the previous study, the amount of ChAT protein decreased in the septum in OBX mice $(65.66 \% \pm 6.24 \%, p<0.05$ vs. sham; Figure $3(\mathrm{~b}))$. We further explored if the recovery of OBX memory impairment in the behavioral analysis is related to the restoration of ChAT expression. Intriguingly, treatment of conditioned medium $(20 \mu \mathrm{L})$ potentiated the gene expression to recover reduced ChAT level in OBX mice $(104.15 \% \pm 16.03 \%, p<0.01$ vs. OBX; Figure $3(b))$. These data suggest that UC MSCs-derived conditioned medium has a potent therapeutic effect on the recovery of ChAT gene expression to restore memory functions. 


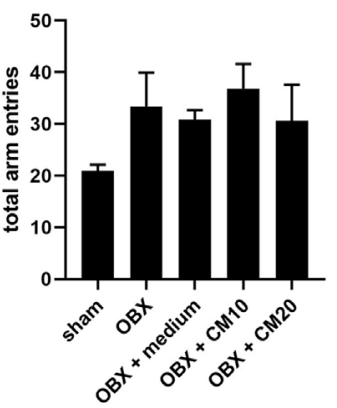

(a)

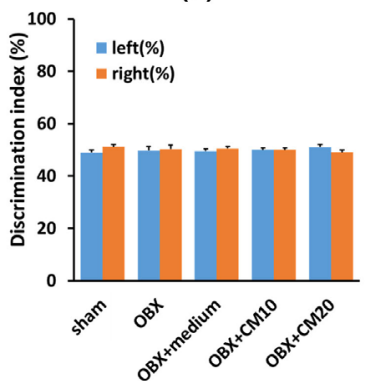

(c)

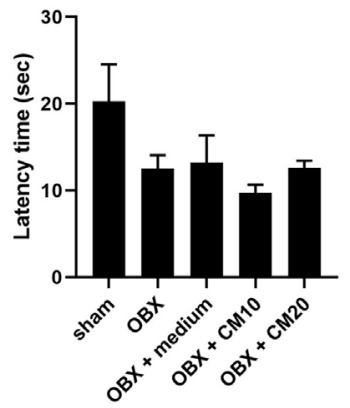

(e)

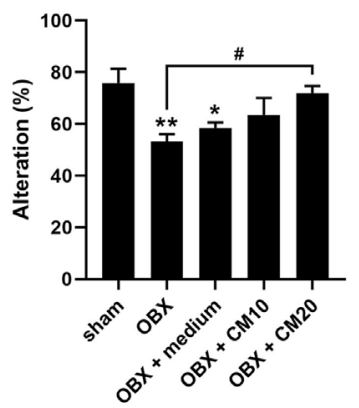

(b)

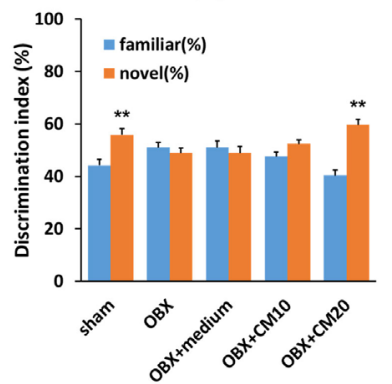

(d)



(f)

Figure 2. Treatment of conditioned medium restored memory impairment of OBX mice. (a) Number of total arm entries and (b) Alternations in a Y-maze task; sham and OBX: $\mathrm{n}$ $=8$; OBX + medium: $\mathrm{n}=7$; OBX $+\mathrm{CM} 10 \mu \mathrm{L}$ or $20 \mu \mathrm{L}: \mathrm{n}=5$. All values are expressed as mean \pm standard error of mean (SEM). Statistical significance was tested by one-way analysis of variance (ANOVA) with post-hoc Tukey's multiple comparison test. ${ }^{\star} p<0.05$, ${ }^{* *} p<0.01$ vs. sham-operated mice; ${ }^{*} p<0.05$ vs. OBX mice. (c) Discrimination index of object exploration during the trial session and (d) The test session in a novel object recognition task; sham: $\mathrm{n}=9$; OBX and OBX + medium: $\mathrm{n}=8$; OBX + CM $10 \mu \mathrm{L}: \mathrm{n}=6$; $\mathrm{OBX}+\mathrm{CM} 20 \mu \mathrm{L}: \mathrm{n}=5$. Error bars represent SEM. ${ }^{* *} p<0.01$ vs. the familiar group by Student's $t$-test. (e) Latency time in fear acquisition session and (f) Test session of passive avoidance task; sham, OBX and OBX + medium: $\mathrm{n}=8, \mathrm{OBX}+\mathrm{CM} 10 \mu \mathrm{L}: \mathrm{n}=6$; OBX + CM $20 \mu \mathrm{L}: \mathrm{n}=5$. Error bars represent SEM. ${ }^{* * * *} p<0.0001$ vs. sham-operated mice; ${ }^{\# \# \# ~} p$ $<0.0001$ vs. OBX mice by one-way ANOVA with post-hoc Tukey's multiple comparison test.

\section{Discussion}

In this study, we demonstrated that conditioned medium derived from cultured UC MSCs potently restored cognition impairment in OBX mice. The therapeutic effect is apparently mediated by the recovery of decreased ChAT gene expression or survival of cholinergic neurons. These results imply that UC MSCs-conditioned 


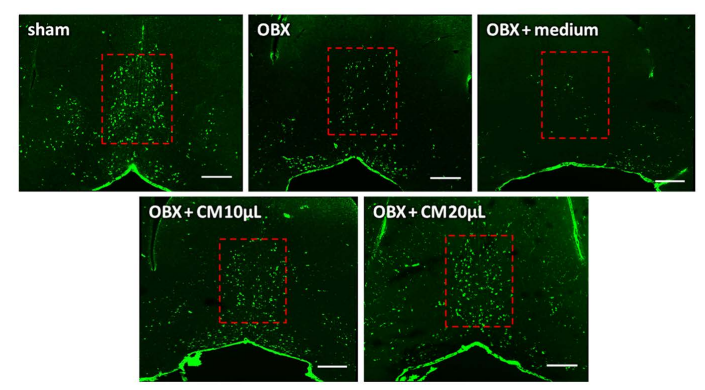

(a)

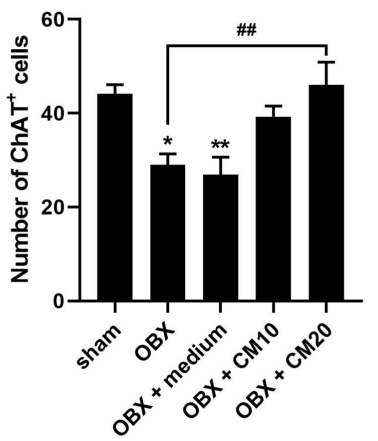

(b)

Figure 3. The administration of conditioned medium recovered the reduction of ChAT immunoreactivity in the medial septum in OBX mice. (a) Representative images of ChAT immunohistochemistry in the medial septum. Images were obtained using a $20 \mathrm{X}$ objective lens. The Scale bars indicate $300 \mu \mathrm{m}$; (b) The numbers of ChAT-positive neurons in the medial septum. The ChAT-positive cells in the red dotted lines were counted. Sham-operated mice and OBX + CM $20 \mu \mathrm{L}: \mathrm{n}=5$; other groups: $\mathrm{n}=6$. Error bars represent SEM. ${ }^{\star} p<$ $0.05,{ }^{* *} p<0.01$ vs. sham-operated mice (sham); ${ }^{\# \#} p<0.01$ vs. OBX mice by one-way ANOVA with post-hoc Tukey's multiple comparison test.

medium has a beneficial effect on the recovery of memory impairment. The cholinergic neurons in the medial septum have an essential role in the cognitive function in AD model mice [10] [17] [18]. We previously demonstrated that neuroprotective compound ST101, an enhancer of T-type calcium channels, rescues the ChAT neurons in the medial septum, and improved cognitive impairment in OBX mice [10]. ST101 is the enhancer of T-type calcium channels in the brain, thereby rescuing the ChAT-positive neurons in OBX. ST101 stimulated BDNF production and protein kinase B (Akt) activity in the medial septum. ST101 stimulated BDNF production and protein kinase B (Akt) activity in the medial septum. In this context, we will further investigate BDNF/Akt signaling after CM administration in the future study.

As to the recovery of the decreased ChAT gene expression observed in this study, the mechanism underlying the protection of ChAT neurons in the present study is still unknown. The previous studies showed that the extracellular vesicles, like exosomes and microvesicles, can be useful for neurological diseases [19]. For example, human adipose tissue-derived mesenchymal stem cells (ADSCs) secrete exosomes, and the treatment suppresses both secreted and intercellular $\mathrm{A} \beta$ levels in the Neuro2a cells [20]. Also, MSCs and exosomes promote cogni- 
tive function and neurogenesis in the subventricular zone of $A \beta$-oligomer injected mice [21]. Although it is unclear whether exosome can pass through the blood-brain barrier (BBB), intranasal administration of conditioned medium was effective in this study. The secreted exosomes may penetrate the nasal sensory neurons in this system. It is also hypothesized that the conditioned medium supply protective cytokines derived from MSCs [22] [23]. Many cytokines are also potential candidates to rescue the cholinergic neurons in the medial septum because the small compounds easily penetrate the brain from nasal. Thus, we propose the pharmacotherapeutics base using our MSC-derived conditioned medium to develop symptomatic and disease-modifying therapy for $\mathrm{AD}$ symptoms. Based on these hypotheses, we will further investigate the mechanism of how the MSCs-conditioned medium shows a therapeutic effect on AD pathology.

In conclusion, we demonstrated that MSCs-derived conditioned medium elicits neuroprotective effects on ChAT neurons in the medium septum, thereby rescuing the cognitive impairment in OBX mice. In the future study, we will define the substances derived from MSCs to develop unique AD therapeutics.

\section{Acknowledgements}

This work was supported in part by grants-in-aid for Scientific Research from the Ministry of Education, Science, Sports and Culture of Japan (Kakenhi 19H03406 to K.F.) and Collaborative Research Fund from Bio Mimetics Sympatheis Inc. (Tokyo) (to K.F.).

\section{Conflicts of Interest}

The authors have no conflict of interest to declare.

\section{References}

[1] Perl, D.P. (2010) Neuropathology of Alzheimer's Disease. Mount Sinai Journal of Medicine, 77, 32-42. http://dx.doi.org/10.1002/msj.20157

[2] Mullard, A. (2018) BACE Failures Lower AD Expectations, again. Nature Reviews Drug Discover, 17, 385. http://dx.doi.org/10.1038/nrd.2018.94

[3] Cummings, J., Lee, G., Ritter, A., Sabbagh, M. and Zhong, K. (2019) Alzheimer's Disease Drug Development Pipeline: 2019. Alzheimer's \& Dementia: Translational Research \& Clinical Interventions, 5, 272-293. http://dx.doi.org/10.1016/j.trci.2019.05.008

[4] Egan, M.F., Kost, J., Tariot, P.N., Aisen, P.S., Cummings, J.L., Vellas, B., Sur, C., Mukai, Y., Voss, T., Furtek, C., Mahoney, E., Harper Mozley, L., Vandenberghe, R., Mo, Y. and Michelson, D. (2018) Randomized Trial of Verubecestat for Mild-toModerate Alzheimer's Disease. The New England Journal of Medicine, 378, 1691-1703. http://dx.doi.org/10.1056/NEJMoa1706441

[5] Salloway, S., Sperling, R., Fox, N.C., Blennow, K., Klunk, W., Raskind, M., Sabbagh, M., Honig, L.S., Porsteinsson, A.P., Ferris, S., Reichert, M., Ketter, N., Nejadnik, B., Guenzler, V., Miloslavsky, M., Wang, D., Lu, Y., Lull, J., Tudor, I.C., Liu, E., Grundman, M., Yuen, E., Black, R., Brashear, H.R. and The Bapineuzumab 301 and 302 Clinical Trial Investigators (2014) Two Phase 3 Trials of Bapineuzumab in 
Mild-to-Moderate Alzheimer's Disease. The New England Journal of Medicine, 370, 322-333. http://dx.doi.org/10.1056/NEJMoa1304839

[6] Wessels, A.M., Tariot, P.N., Zimmer, J.A., Selzler, K.J., Bragg, S.M., Andersen, S.W., Landry, J., Krull, J.H., Downing, A.M., Willis, B.A., Shcherbinin, S., Mullen, J., Barker, P., Schumi, J., Shering, C., Matthews, B.R., Stern, R.A., Vellas, B., Cohen, S., MacSweeney, E., Boada, M. and Sims, J.R. (2019) Efficacy and Safety of Lanabecestat for Treatment of Early and Mild Alzheimer Disease: The AMARANTH and DAYBREAK-ALZ Randomized Clinical Trials. JAMA Neurology, 77, 199-209. http://dx.doi.org/10.1001/jamaneurol.2019.3988

[7] Hozumi, S., Nakagawasai, O., Tan-No, K., Niijima, F., Yamadera, F., Murata, A., Arai, Y., Yasuhara, H. and Tadano, T. (2003) Characteristics of Changes in Cholinergic Function and Impairment of Learning and Memory-Related Behavior Induced by Olfactory Bulbectomy. Behavioural Brain Research, 138, 9-15.

[8] Aleksandrova, I.Y., Kuvichkin, V.V., Kashparov, I.A., Medvinskaya, N.I., Nesterova, I.V., Lunin, S.M., Samokhin, A.N. and Bobkova, N.V. (2004) Increased Level of $\beta$-Amyloid in the Brain of Bulbectomized Mice. Biochemistry (Moscow), 69, 176-180. http://dx.doi.org/10.1023/b:biry.0000018948.04559.ab

[9] Yamamoto, Y. and Fukunaga, K. (2013) Donepezil Rescues the Medial Septum Cholinergic Neurons via Nicotinic ACh Receptor Stimulation in Olfactory Bulbectomized Mice. Advances in Alzheimer's Disease, 2, 161-170. http://dx.doi.org/10.4236/aad.2013.24021

[10] Han, F., Shioda, N., Moriguchi, S., Yamamoto, Y., Raie, A.Y., Yamaguchi, Y., Hino, M. and Fukunaga, K. (2008) Spiro[Imidazo[1,2- $\alpha$ ]Pyridine-3,2-Indan]-2(3H)-One (ZSET1446/ST101) Treatment Rescues Olfactory Bulbectomy-Induced Memory Impairment by Activating $\mathrm{Ca}^{2+} /$ Calmodulin Kinase II and Protein Kinase $\mathrm{C}$ in Mouse Hippocampus. Journal of Pharmacology and Experimental Therapeutics, 326, 127-134. http://dx.doi.org/10.1124/jpet.108.137471

[11] Yamamoto, Y., Shioda, N., Han, F., Moriguchi, S. and Fukunaga, K. (2013) Novel Cognitive Enhancer ST101 Enhances Acetylcholine Release in Mouse Dorsal Hippocampus through T-Type Voltage-Gated Calcium Channel Stimulation. Journal of Pharmacological Sciences, 121, 212-226.

[12] Pittenger, M.F., Mackay, A.M., Beck, S.C., Jaiswal, R.K., Douglas, R., Mosca, J.D., Moorman, M.A., Simonetti, D.W., Craig, S. and Marshak, D.R. (1999) Multilineage Potential of Adult Human Mesenchymal Stem Cells. Science, 284, 143-147. http://dx.doi.org/10.1126/science.284.5411.143

[13] Urrutia, D.N., Caviedes, P., Mardones, R., Minguell, J.J., Vega-Letter, A.M. and Jofre, C.M. (2019) Comparative Study of the Neural Differentiation Capacity of Mesenchymal Stromal Cells from Different Tissue Sources: An Approach for Their Use in Neural Regeneration Therapies. PLoS ONE, 14, e0213032. http://dx.doi.org/10.1371/journal.pone.0213032

[14] Yun, H.M., Kim, H.S., Park, K.R., Shin, J.M., Kang, A.R., il Lee, K., Song, S., Kim, Y.B., Han, S.B., Chung, H.M. and Hong, J.T. (2013) Placenta-Derived Mesenchymal Stem Cells Improve Memory Dysfunction in an $\mathrm{A} \beta_{1-42}$-Infused Mouse Model of Alzheimer's Disease. Cell Death \& Disease, 4, e958. http://dx.doi.org/10.1038/cddis.2013.490

[15] Xie, Z.H., Liu, Z., Zhang, X.R., Yang, H., Wei, L.F., Wang, Y., Xu, S.L., Sun, L., Lai, C., Bi, J.Z. and Wang, X.Y. (2016) Wharton's Jelly-Derived Mesenchymal Stem Cells Alleviate Memory Deficits and Reduce Amyloid- $\beta$ Deposition in an APP/PS1 Transgenic Mouse Model. Clinical and Experimental Medicine, 16, 89-98. http://dx.doi.org/10.1007/s10238-015-0375-0 
[16] Yabuki, Y., Matsuo, K., Izumi, H., Haga, H., Yoshida, T., Wakamori, M., Kakei, A., Sakimura, K., Fukuda, T. and Fukunaga, K. (2017) Pharmacological Properties of SAK3, a Novel T-Type Voltage-Gated $\mathrm{Ca}^{2+}$ Channel Enhancer. Neuropharmacology, 117, 1-13. http://dx.doi.org/10.1016/j.neuropharm.2017.01.011

[17] Mehla, J., Lacoursiere, S.G., Lapointe, V., McNaughton, B.L., Sutherland, R.J., McDonald, R.J. and Mohajerani, M.H. (2019) Age-Dependent Behavioral and Biochemical Characterization of Single APP Knock-In Mouse (APP ${ }^{\text {NL-G-F/NL-G-F }}$ ) Model of Alzheimer's Disease. Neurobiology of Aging, 75, 25-37. http://dx.doi.org/10.1016/j.neurobiolaging.2018.10.026

[18] Han, F., Shioda, N., Moriguchi, S., Qin, Z.H. and Fukunaga, K. (2008) The Vanadium (IV) Compound Rescues Septo-Hippocampal Cholinergic Neurons from Neurodegeneration in Olfactory Bulbectomized Mice. Neuroscience, 151, 671-679. http://dx.doi.org/10.1016/j.neuroscience.2007.11.011

[19] Keshtkar, S., Azarpira, N. and Ghahremani, M.H. (2018) Mesenchymal Stem CellDerived Extracellular Vesicles: Novel Frontiers in Regenerative Medicine. Stem Cell Research \& Therapy, 9, Article No. 63. http://dx.doi.org/10.1186/s13287-018-0791-7

[20] Katsuda, T., Tsuchiya, R., Kosaka, N., Yoshioka, Y., Takagaki, K., Oki, K., Takeshita, F., Sakai, Y., Kuroda, M. and Ochiya, T. (2013) Human Adipose Tissue-Derived Mesenchymal Stem Cells Secrete Functional Neprilysin-Bound Exosomes. Scientific Reports, 3, Article No. 1197. http://dx.doi.org/10.1038/srep01197

[21] Reza-Zaldivar, E.E., Hernandez-Sapiens, M.A., Gutierrez-Mercado, Y.K., Sandoval-Avila, S., Gomez-Pinedo, U., Marquez-Aguirre, A.L., Vazquez-Mendez, E., Padilla-Camberos, E. and Canales-Aguirre, A.A. (2019) Mesenchymal Stem Cell-Derived Exosomes Promote Neurogenesis and Cognitive Function Recovery in a Mouse Model of Alzheimer's Disease. Neural Regeneration Research, 14, 1626-1634. http://dx.doi.org/10.4103/1673-5374.255978

[22] Perl, D.P., Sugaya, H., Yoshioka, T., Kato, T., Taniguchi, Y., Kumagai, H., Hyodo, K., Ohneda, O., Yamazaki, M. and Mishima, H. (2018) Comparative Analysis of Cellular and Growth Factor Composition in Bone Marrow Aspirate Concentrate and Platelet-Rich Plasma. Bone Marrow Research, 2018, Article ID: 1549826.

[23] Hofer, H.R. and Tuan, R.S. (2016) Secreted Trophic Factors of Mesenchymal Stem Cells Support Neurovascular and Musculoskeletal Therapies. Stem Cell Research \& Therapy, 7, Article No. 131. http://dx.doi.org/10.1186/s13287-016-0394-0 